\title{
Metabolic profiling to discriminate the biochemical basis of Powdery Mildew resistance in Green Gram (Vigna radiata)
}

\section{Soundhiriyan PV', Kamalakannan $\mathbf{A}^{1}$, Paranitharan $\mathbf{V}^{1}$, Jeyakumar $\mathbf{P}^{2}$ and Latha TKS ${ }^{1}$}

\footnotetext{
${ }^{1}$ Department of Plant Pathology, Centre for Plant Protection Studies, Tamil Nadu Agricultural University, Coimbatore, Tamil Nadu - 641003, India

${ }^{2}$ Department of Crop physiology, Tamil Nadu Agricultural University, Coimbatore, Tamil Nadu - 641003, India
}

Soundhiriyan PV, Kamlakannan A, Paranitharan V, Jeyakumar P, Latha TKS 2019 - Metabolic profiling to discriminate the biochemical basis of Powdery Mildew resistance in Green Gram (Vigna radiata). Plant Pathology \& Qurantine 9(1), 210-218, Doi 10.5943/ppq/9/1/19

\begin{abstract}
Knowledge of the complexity of mechanisms responsible for resistance to powdery mildew infection of green gram cultivar TARM-18, is necessary for strategies to be defined which will improve resistance in highly susceptible crop species. Metabolic profiles of resistant and susceptible cultivars were analysed by Gas Chromatography /EI-TOF-Mass Spectrometry. The metabolites were identified manually using AMDIS software integrated with NIST library 2014. Different metabolites elaborated under compatible and incompatible interactions have been tentatively identified as the top five spectral hits with the NIST-05 and GMD libraries, using retention times as reference. Out of 20 metabolites identified, found 6 metabolites viz., Hexadeconic acid, alanine, validane, dimethyl amino benzaldehyde, putrescine and methy ethyl trisulfide were up-regulated in resistant green gram genotypes upon pathogen inoculation and contributed for resistance.
\end{abstract}

Key words - Erysiphe polygoni - GC-MS - Metabolomics - Susceptibility

\section{Introduction}

Legumes are important protein (22-24\%) source for food diet of humans. The Green gram [Vigna radiata (L.) Wilcjeck] is being widely cultivated in the region of Tropical Asia (Shanmugasundaram \& Kim 1996). India is the largest producer of green gram Contributing 45\% of total world production (Poehlman 1992) and cultivated as Kharif crop. The Indian national average yield of green gram is $468 \mathrm{~kg} \mathrm{ha}^{-1}$ and it contributed about $8 \%$ of total pulse export during 2016-2017. Significant foliar diseases affecting the green gram is Powdery mildew (Erysiphe polygoni), Macrophomina blight (Macrophomina phaseolina) and Cercospora leaf spot (Cercospora canescens) and yellow mosaic (Green gram Yellow Mosaic Virus). Among all the disease, Powdery mildew can cause yield loss from 9-50 per cent and maximum damage occurs when infects just before flowering (Pande et al. 2009, Reddy et al. 2008). PM has the extensive geographical range and also have varied host range (Moseman 1966, Poehlman 1992) and severity is more during cool-dry months. Powdery mildew disease was managed mainly by chemical spray and genetic resistance but this method has not been satisfactory considering the loss of 
effectiveness of genes as new race evolved and use of chemicals is known to cause undesirable effects such as residual toxicity, development of resistance and not always economically feasible (Li et al. 2016). Cultivation of resistant genotypes is an effective and cheaper method to combat the disease and the resistant genotypes for PM are TARM-18, TAU-95-1, TM-96-2, VG-1, HPPC 16, HPCC 77, HPCC 95, Rachana, Pant P-9, PH-1, JP 514-A, VG-9 (Jayalakshmi et al. 2003, Malhotra \& Singh 2000, Pathak et al. 2015). But several genotypes need to be screened to identify resistant genotypes or to locate the source of resistance and it is time consuming process.

In order to pyramid genes and to enhance the level of resistance in elite cultivars, the resistance genes and alleles of all types are needed to be identified and included in breeding programmes (Yang et al. 2005). Hence, apart from the studies on pathogenesis and host-pathogen interactions using conventional methods, the outcome of 'omics' studies will aid in a better understanding of complex response to pathogen infection (Tarpley et al. 2005). It has been well documented that during early phases of infection by plant pathogens, a series of physiological and biochemical changes, together with the molecular response occur in plants. Among them, metabolic alteration is a common response in both compatible and incompatible plant-pathogen interactions (Fiehn et al. 2000a). The disease resistance or susceptibility depends on physiology of plants differing in their metabolic activities (Hamzehzarghani et al. 2005, Paranidharan et al. 2008). Hence, comparing metabolic response of resistant and susceptible genotypes upon infection by pathogens possibly represents a powerful tool to unravel the biochemical pathways involved in plant defense.

The metabolomics is an evolving field in systems biology and it is not only complementary to transcriptomics and proteomics but also have special advantage that they are often the downstream results of gene expression (Fiehn 2002). This technology has found momentum to identify and quantify all the metabolites in an organism or a biological system (Schauer et al. 2006). Metabolites have been linked to specific genomic positions, and a set of co-localized genes/QTL have been proven to regulate certain metabolic pathways leading to the production of a series of metabolites that are in turn linked to phenotypes (Keurentjes et al. 2006, Schauer \& Fernie 2006).

It is possible that the cultivars of green gram varying in resistance to Erysiphe polygoni also would produce certain metabolites to resist pathogen invasion. Such metabolites can be used as biomarkers or linked to genomic locations on chromosomes and in the breeding programmes.

Host plant resistance is the most promising method to minimize yield loss due to Powdery mildew disease. Several major genes with complete resistance to a specific subset of isolate have been deployed in the development of varieties. The resistance in several varieties having major genes for Powdery mildew often breaks down due to the evolution of virulent races of pathogen after few years of the release of resistant varieties. Host plant and pathogen interaction were exciting in terms of richness of metabolism and regulation of metabolite and may act as an ideal model for developing and standardizing of high-throughput metabolomics. It may be possible that the genotype of green gram varying in resistant also would produce certain metabolites to resist invasion of pathogen.

Hence, it is important to know the metabolite produced before and after infection in resistant and susceptible genotype, which helps to identify the resistant source at initial stages.

\section{Materials and methods}

\section{Collection and isolation of Erysiphe polygoni}

Powdery mildew infected green gram leaf samples were collected from Department of Pulses, Tamil Nadu Agricultural University, Coimbatore-India during July 2017. Although Powdery mildew was an obligate pathogen, we cannot able to maintain culture on artificial media. So sick plot for Powdery mildew was maintained throughout the entire research period to get fresh inoculum. 
The Powdery mildew spores from the infected samples were collected from severely infected leaf using a camel brush in $1.5 \mathrm{~mL}$ micro-centrifuge tube containing one $\mathrm{ml}$ of double sterile water under aseptic condition and it is further used for spraying in sick plot.

Powdery mildew fungus was maintained under natural conditions during Kharif 2017-2018. Powdery mildew susceptible green gram variety SML 1082 was raised in micro plot. All the recommended package of practices were followed in raising the crop with protective irrigations. Conidia were collected from the infected green gram leaves using a camel brush in sterilized 1.5mL micro-centrifuge tube containing one $\mathrm{ml}$ of double sterile water under aseptic condition, desirable concentration of conidial suspension $\left(10^{6} \mathrm{conidia} / \mathrm{ml}\right)$ was prepared. Glycerol at the rate of ten microliter was added in micro-centrifuge tube and inoculated on the healthy leaves at 30 days after sowing by spray method. The pathogen was maintained by continuous sowing of susceptible green gram plants (SML-1028) for further studies.

\section{Pathogenicity of Erysiphe polygoni in green gram}

Conidial suspension of Erysiphe polygoni was prepared by scrapping the conidia from the infected leaves. The conidial concentration was adjusted to $10^{6} \mathrm{conidia} / \mathrm{ml}$ using a haemocytometer. The suspension was sprayed on the healthy leaves of 30 days old green gram genotype SML-1082 grown in pots under glass house condition. The plants were covered by polythene bags for 24 hours after inoculation to maintain humidity of 80 per cent for disease development. The development of disease was observed at periodical interval after inoculation (Vimala \& Suriachandraselvan 2008).

\section{Metabolic profiling of susceptible and resistant green gram genotypes inoculated with Erysiphe polygoni}

\section{Greenhouse studies}

The experiment was conducted in earthen pots (30 cm dia.) filled with $10 \mathrm{~kg}$ of autoclaved pot mixture (Sterilized). Seeds of green gram genotypes viz., SML 1082 (Highly susceptible) and TARM 18 (Highly resistant) were sown at three seeds per pot. Plants were grown in controlled condition. The recommended package of practices was followed to raise the green gram crop. Artificial inoculation of Powdery mildew pathogen was done by spraying of conidial suspension $\left(10^{6}\right.$ conidia/ml). Pathogen treated plants (sprayed with Powdery mildew conidia) and non-treated plants (control) were kept separately in different chamber under controlled conditions.

\section{Sampling for metabolite extraction}

Sampling was carried out as described by Sana et al. (2010). Leaf samples from both inoculated and control plants of each green gram genotype was collected at $0 \mathrm{~h}$ (immediately after inoculation) and 24 h, 48 h \& 72 h of post inoculation days. Non-treated plants (control plans) and pathogen-inoculated plants were used for comparison. Three replicates were maintained for each time points. Samples were frozen immediately in liquid nitrogen and stored at $-70^{\circ} \mathrm{C}$. These stored powdered sample were further used for the metabolite extraction.

\section{Metabolite extraction and derivatization}

Polar primary metabolites were extracted from the leaf tissues and then subjected to derivatization by following the procedure described by Fiehn et al. (2000b), Lisec et al. (2006) and Erban et al. (2007). Green gram leaf samples were ground in a sterilized, pre-cooled pestle and mortar. The powdered leaf (300 mg) was transferred to $2 \mathrm{ml}$ round- bottom micro-centrifuge tubes followed by $1.4 \mathrm{ml}$ of $100 \%$ methanol and $50 \mu \mathrm{L}$ of internal standard ribitol were added and mixed well by vortex. Then, $50 \mu \mathrm{L}$ of de-ionized water was added. The mixtures was incubated at $70^{\circ} \mathrm{C}$ for 15 minutes on a shaker at $950 \mathrm{rpm}$ and then centrifuged at 12,500rpm for 20 minutes. The supernatant was transferred into Ultafree-CL $0.22 \mu \mathrm{L}$ filter tubes and $1.4 \mathrm{ml}$ of water was added in the same tube. Further, $750 \mu 1$ of chloroform was added to the pellet then vortexed for uniform mixing and shaked at $37^{\circ} \mathrm{C}$ for 10 minutes. This mixture was further centrifuged at $12,500 \mathrm{rpm}$ for 
20 minutes. The supernatant was transfered and combined into the same Ultafree-CL $0.22 \mu \mathrm{L}$ filter tubes. This tube was then vortexed and centrifuged at $4000 \mathrm{rpm}$ for 15 minutes. The upper polar phase was separated into new eppendorf tubes and closed the tubes with parafilm and punched a little hole in the parafilm and dried in a SpeedVac concentrator overnight. The dried samples were then stored at $-70^{\circ} \mathrm{C}$ until derivatization. For derivatization, $300 \mu 1$ of methoxyamination reagent (5 $\mathrm{mg}$ of 4-dimethylaminopyridine and $40 \mathrm{mg}$ of methoxyamine hydrochloride dissolved in $1 \mathrm{ml}$ of pyridine) was added to the micro-centrifuge tube and shaken at $37^{\circ} \mathrm{C}$ for 2 hours. Then the sample was vortexed every 30 minutes during two hours of shaking to dissolve the sample completely in the reagent. After methoxyamination, the samples were centrifuged at 10,000 rpm for one minute. The supernatant $(40 \mu \mathrm{l})$ from the above was transferred to $1.5 \mathrm{ml}$ of micro-centrifuge tube followed by $70 \mu \mathrm{l}$ of N, O-Bis (trimethylsilyl) trifluoroacetamide (BSTFA) and $10 \mu \mathrm{l}$ of retention time standards (n-alkanes) were added to the same tube and shaken at $37^{\circ} \mathrm{C}$ for 30 minutes. The nalkanes mixture was prepared by using pyridine at a final concentration of $0.22 \mathrm{mg} / \mathrm{ml}$ each. The samples were then centrifuged at 10,000rpm for one minute and $95 \mu 1$ was transferred to GC.MS glass vial for analysis using GC/EI-TOF-MS.

\section{Gas chromatography and mass spectrometry (GC-MS) analysis}

The GC-MS was performed as per the method described by (Belal et al. 2014). The sample was injected into "PERKIN ELMER CLARUS SQ8C Gas Chromatograph with DB-5 MS column (30 $\mathrm{m} \times 0.25 \mathrm{~mm}, 0.25 \mu \mathrm{m}$ film thickness)”. The temperature was programmed at $30^{\circ} \mathrm{C}$ (1 minutes), $230^{\circ} \mathrm{C}$ (20 minutes) at the rate of $4^{\circ} \mathrm{C}$ per minute. The detector was heated at $250^{\circ} \mathrm{C}$, injector at $230^{\circ} \mathrm{C}$. Helium was used as carrier gas at 5 Psi pressure. Mass spectra were obtained by electron ionization at $70 \mathrm{eV}$.

\section{Identification of metabolites}

Different metabolites elaborated under the compatible and incompatible interactions of resistant and susceptible genotypes in response to Erysiphe polygoni pathogenesis have been tentatively identified as the top five spectral hits with the NIST-05 National Institute of Standards Technology. Palisade Corp., NY and Golm Metabolome Database (GMD) (Kopka et al. 2005) libraries, using retention times as reference. For each peak, the spectra of four replicates of a treatment were compared and matched with that of NIST/GMD spectra. Analytes with good match factor (>60\%) were considered and tentatively identified.

\section{Results and discussion}

In the present study, Powdery mildew resistant (TARM-18) and susceptible (SML-1082) green gram genotypes were used to understand the mechanism of resistance against Erysiphe polygoni pathogen at metabolomic level by using GC-MS analysis. About 50 metabolites for each treatment was generated but a total of 20 metabolites were taken due to time and cost factor. The GC-MS output on scans and mass abundance were possessed and the metabolites were identified manually using AMDIS software integrated with NIST library 2014. In total, 20 metabolites were tentatively identified and were classified into different chemical groups (Table 1).

Among these, eight metabolites were commonly detected in both the genotypes during 0,24 , 48, 72 hours of post-inoculation. Whereas hexadeonic acid, alanine, butyl acetate, diamino benzaldehyde and putrescine, methy ethy trisulfide, pyridine, hydroxyheptanoic acid were detected only the resistant genotype TARM-18. From the 20 metabolites identified, six metabolites were found to be upregulated in resistant green gram genotype TARM-18 as a result of pathogen infection. Three metabolites viz., hexadeconic acid, alanine and quinic acid were upregulated at 72 hours of inoculation of E. polygoni in resistant genotype. Whereas, Dimethyl amino benzaldehyde, putrescine and methyl ethyl trisulfide were upregulated from 24 hours of inoculation. The compound 2-hexanone was induced in both susceptible and resistant genotype at 72 hours of post inoculation. The metabolite 2-hexanone were produced in both the susceptible and resistant genotype at 72 hours of inoculation. 
The other metabolites include propylene glycol, propyl acetate, methionine, glucose, sucrose, malic acid, oxalic acid, raffanose were detected in both resistant and susceptible genotypes. Whereas, propionic acid and lauric acid were down-regulated from 24 hours of post-infection both in resistant and susceptible genotype. Ethyl propionate were detected in both susceptible and resistant genotype and were down regulated after 72 hours of inoculation.

In the present study, E. polygoni inoculated plants of TARM-18 showed induction of quinic acid and dimethyl amino benzaldehyde. It has been reported that early induction of phenylpropanoid pathway leads to production of both anti-microbial secondary metabolites and lignin/suberin precursors for cell-wall strengthening in resistance responses (Fraser \& Chapple 2011, Hückelhoven 2007, Kawasaki et al. 2006). Methyl ethyl trisulfide, a methyl ester compound responsible for inter-and intra-organism communication between plants, antagonists and mutualistic symbionts both below and above ground (Kanchiswamy et al 2015). This showed that the infection by $E$. polygoni substantially altered the metabolic profile of green gram.

Plant-pathogen interactions are interesting in terms of metabolite richness and metabolism regulation and can serve as an ideal model for the development and standardization of highthroughput metabolomics. It is possible that the genotype of green gram varying in resistance also would produce certain metabolites to resist pathogen invasion. Melabolomics is a technology geared to identify and quantify all the metabolites in a biological system (Schauer \& Fernie 2006). Metabolites have been linked to specific genomic positions, and a set of co-localized genes/QTLs have been proven to regulate certain metabolic pathways leading to the production of a series of metabolites that are in turn linked to phenotypes (Keurentjes et al. 2006, Schauer \& Fernie 2006).

Metabolomics is an evolving field in systems biology and it is not only complementary to transcriptomics and proteomics but also have a special advantage that they are often the downstream results of gene expression (Fiehn 2002). In metabolite profiles of potato following pathogen inoculation, 106 peaks were detected, of which 95 metabolites were tentatively identified. Abundance of 42 metabolites were knowingly increased or decreased, and these metabolites were designated as Pathogenesis-Related (PR) metabolites. Plausible satellite-networks of metabolic pathways leading to up-regulation of these families of amino acids and other secondary metabolites, and their potential application for evaluation of horizontal resistance in potato against late blight pathogen was studied by Abu-Nada et al. (2007).

Alanine has an important role in plant metabolism and is involved in enhanced defence response to fungi, oomycetes and bacteria (Rojas et al. 2014). The putrescine is one of the aliphatic amines found in all plant cells. It occurs in plants in free form as cations and are often conjugated to small molecules like phenolic aids and also to various macromolecules, such as DNA and RNA. They are necessary for the successful replication of most cells. This have been implicated in the regulation of senescence and morphogenesis in plants, as well as in plant responses to environmental stress such as biotic and abiotic stress. Putrescine is synthesized in plants through decarboxylation of either ornithine or arginine and the respective reactions are catalysed by the enzymes ornithinc decarboxylase and arginine decarboxylase (Walters \& Mackintosh 1997). Hexadeconic acid, 16 carbon molecule with no double bond which constitutes complex lipids are essential components of cellular membrane. This fatty acid derivative may act as a signaling molecule, modulating normal and disease related physiologies in plants (Kachroo \& Kachroo 2009).

Quinic acid was thought to be a reserve compound of the shikimate pathway, which is used for biosynthesis of phenolics. Quinate dehydrogenase (QDH) catalyzes the inter-conversion of quinic acid and 3-dehydroquinic acid and thus connects the pool of quinate with the shikimate pathway. Quinatehydrolyase convert quinic acid directly into shikimic acid in Zea mays cells (Boudet et al. 1985). Shikimic acid and its pathway intermediates act as a precursors for synthesis of phenylpropanoid compounds such as phenyalanine, cinnamic acid and coumaric acid, thus in turn involved in the production of defensive lignans and lignin, phenylpropenes and coumarins (Dewick 2009). Nuclear Magnetic Resonance Spectroscopy and GC/LC-MS/MS analysis of rice leaves aided to identify wide range of metabolites (Jones et al. 2011). 
Thomas et al. (2006) carried out metabolite profiling and characterization of somaclonal variants in tea (Camellia spp.) for identifying productive and quality accession. Nuclear Magnetic Resonance (NMR) spectroscopy and Gas and Liquid Chromatography Tandem Mass spectrometry (GC/LC-MS/MS) analysis of rice leaves from compatible and incompatible interaction with $M$. grisea yielded 93 compounds from both organic and aqueous phase extracts (Jones et al. 2011). The authors observed the induction of metabolites $24 \mathrm{~h}$ post inoculation and identified the largest change of metabolite namely, alanine which was $\sim 30 \%$ higher in the leaves from the compatible, compared to the resistant plants. They also hypothesized and suggested that successful entry of pathogen will trigger an increase in alanine levels to promote cell death of the infected tissue which $M$. grisea then exploits to facilitate invasion.

Table 1 Changes in metabolites in susceptible (SML-1082) and resistant (TARM-18) green gram genotype at $0,24,48$ and 72 hours of inoculation with Erysiphe polygoni

\begin{tabular}{|c|c|c|c|c|c|c|c|c|c|c|c|c|}
\hline \multirow[t]{2}{*}{ S.No. } & \multirow[t]{2}{*}{ Metabolites } & \multirow{2}{*}{$\begin{array}{l}\text { Retention } \\
\text { Index }\end{array}$} & \multirow{2}{*}{$\begin{array}{c}\text { Molecular } \\
\text { Formula }\end{array}$} & \multirow{2}{*}{$\begin{array}{c}\text { Molecular } \\
\text { Weight }\end{array}$} & \multicolumn{4}{|c|}{$\begin{array}{c}\text { Susceptible } \\
\text { (SML-1082) }\end{array}$} & \multicolumn{4}{|c|}{$\begin{array}{c}\text { Resistant } \\
\text { (TARM-18) }\end{array}$} \\
\hline & & & & & $\mathbf{0}$ & 24 & 48 & 72 & $\mathbf{0}$ & 24 & 48 & 72 \\
\hline 1 & Malic acid & 1294 & $\mathrm{C}_{4} \mathrm{H}_{6} \mathrm{O}_{5}$ & 134.0874 & + & + & + & + & + & + & + & + \\
\hline 2 & Methionine & 1304 & $\mathrm{C}_{5} \mathrm{H}_{11} \mathrm{NO}_{2} \mathrm{~S}$ & 149.2113 & + & + & + & + & + & + & + & + \\
\hline 3 & Oxalic acid & 933 & $\mathrm{C}_{2} \mathrm{H}_{2} \mathrm{O}_{4}$ & 94.018 & + & + & + & + & + & + & + & + \\
\hline 4 & Propylene glycol & 724 & $\mathrm{C}_{3} \mathrm{H}_{8} \mathrm{O}_{2}$ & 76.05243 & + & + & + & + & + & + & + & + \\
\hline 5 & Propyl acetate & 811 & $\mathrm{C}_{5} \mathrm{H}_{10} \mathrm{O}_{2}$ & 102.0681 & + & + & + & + & + & + & + & + \\
\hline 6 & Glucose & 1974 & $\mathrm{C}_{6} \mathrm{H}_{12} \mathrm{O}_{6}$ & 180.156 & + & + & + & + & + & + & + & + \\
\hline 7 & Raffinose & 1876 & $\mathrm{C}_{18} \mathrm{H}_{32} \mathrm{O}_{16}$ & 504.438 & + & + & + & + & + & + & + & + \\
\hline 8 & Sucrose & 1096 & $\mathrm{C}_{12} \mathrm{H}_{22} \mathrm{O}_{11}$ & 342.2965 & + & + & + & + & + & + & + & + \\
\hline 9 & Hydroxyheptanoic acid & 960 & $\mathrm{C}_{7} \mathrm{H}_{14} \mathrm{O}_{3}$ & 146.094 & - & - & - & - & + & + & + & + \\
\hline 10 & Pyridine & 674 & $\mathrm{C}_{5} \mathrm{H}_{5} \mathrm{~N}$ & 79.0422 & - & - & - & - & + & + & + & + \\
\hline 11 & Methyl ethyl trisulfide & 1072 & $\mathrm{C}_{3} \mathrm{H}_{8} \mathrm{~S}_{3}$ & 139.9788 & - & - & - & - & - & + & + & + \\
\hline 12 & Putrescine & 905 & $\mathrm{C}_{4} \mathrm{H}_{12} \mathrm{~N}_{2}$ & 88.10005 & - & - & - & - & - & + & + & + \\
\hline 13 & Dimethylaminobenzaldehyde & 1406 & $\mathrm{C}_{9} \mathrm{H}_{11} \mathrm{NO}$ & 149.0841 & - & - & - & - & - & - & + & + \\
\hline 14 & Quinic acid & 1842 & $\mathrm{C}_{7} \mathrm{H}_{12} \mathrm{O}_{6}$ & 192.167 & - & - & - & - & - & - & - & + \\
\hline 15 & Alanine & 874 & $\mathrm{C}_{3} \mathrm{H}_{7} \mathrm{NO}_{2}$ & 89.04768 & - & - & - & - & - & - & - & + \\
\hline 16 & Hexadecanoic acid & 1780 & $\mathrm{C}_{16} \mathrm{H}_{32} \mathrm{O}_{2}$ & 256.2402 & - & - & - & - & - & - & - & + \\
\hline 17 & 2-Hexanone & 908 & $\mathrm{C}_{6} \mathrm{H}_{12} \mathrm{O}$ & 100.0888 & - & - & - & + & - & - & + & + \\
\hline 18 & Lauric acid & 1298 & $\mathrm{C}_{12} \mathrm{H}_{24} \mathrm{O}_{2}$ & 200.1776 & + & - & - & - & + & - & - & - \\
\hline 19 & Propynoic acid & 674 & $\mathrm{C}_{3} \mathrm{H}_{2} \mathrm{O}_{2}$ & 70.00548 & + & - & - & - & + & - & - & - \\
\hline 20 & Ethyl propionate & 811 & $\mathrm{C}_{5} \mathrm{H}_{10} \mathrm{O}_{2}$ & 102.0681 & + & + & + & - & + & + & + & - \\
\hline
\end{tabular}


The involvement of these compounds in various defense mechanisms in plants against wide range of pathogens has been well documented. Mass spectrometry (MS), nuclear magnetic resonance (NMR) spectroscopy provides a powerful complementary technique for the identification and quantitative analysis of plant metabolites either in vivo or in tissue extracts. Metabolite fingerprinting by NMR is a fast, convenient, and effective tool for discriminating between groups of related samples and it identifies the most important regions of the spectrum for further analysis (Krishnan et al. 2005).

\section{Conclusion}

The present investigation provides new insight into the mechanisms of resistance to Erysiphe polygoni in green gram carrying multiple resistance genes at the metabolite level and indicates a considerable number of potential metabolic targets for further in-depth investigations. To our knowledge this study represents the first comprehensive analysis of metabolic changes in green gram during compatible and incompatible interactions with Erysiphe polygoni.

\section{Declaration of interest}

The authors report no conflicts of interest. The authors alone are responsible for the content and writing of this article.

\section{Acknowledgements}

The support provided by The Professor and Head (Department of Plant Pathology), Director (CPPS) and The Dean (SPGS), Tamil Nadu Agricultural University are deeply acknowledged. The authors would also like to acknowledge DST - FIST for providing infrastructure facilities and UGC-SAP -DRS operated in Department of Plat Pathology for availing fund facilities and also Dr. Soframanien from Baba Atomic Research Centre, Mumbai \& Dr. M. Adinarayana, LAM centre, ANGRU for providing green gram seed material.

\section{References}

Abu-Nada Y, Kushalappa AC, Marshall WD, Al-Mughrabi K, Murphy A. 2007 - Temporal dynamics of pathogenesis-related metabolites and their plausible pathways of induction in potato leaves following inoculation with Phytophthora infestans. European Journal of Plant Pathology 118, 375-391.

Belal TS, Awad T, Clark CR. 2014 - Stability-indicating determination of trimetazidine dihydrochloride in the presence of two of its related substances using a direct GC/MS method. Journal of AOAC International 97, 1514-1518.

Boudet AM, Graziana A, Ranjeva R. 1985 - Recent advances in the regulation of the prearomatic pathway. In InThe Biochemistry of Plant Phenolics 135-160.

Dewick PM. 2009 - Medicinal Natural Products: A Biosynthetic Approach: Third Edition Medicinal Natural Products: A Biosynthetic Approach: Third Edition. John Wiley \& Sons.

Erban A, Schauer N, Fernie AR, Kopka J. 2007 - Nonsupervised Construction and Application of Mass Spectral and Retention Time Index Libraries From Time-of-Flight Gas Chromatography-Mass Spectrometry Metabolite Profiles. In Methods in molecular biology 19-38.

Fiehn O. 2002 - Metabolomics - The link between genotypes and phenotypes. Plant Molecular Biology 48, 155-171.

Fiehn O, Kopka J, Dormann P, Altmann T, Trethewey RN, Willmitzer L. 2000b - Metabolite profiling for plant functional genomics. Nature Biotechnology 18, 1157-1161.

Fiehn O, Kopka J, Trethewey RN, Willmitzer L. 2000a - Identification of uncommon plant metabolites based on calculation of elemental compositions using gas chromatography and quadrupole mass spectrometry. Analytical Chemistry 72, 3573-3580. 
Fraser CM, Chapple C. 2011 - The phenylpropanoid pathway in Arabidopsis. The Arabidopsis Book. e0152.

Hamzehzarghani H, Kushalappa AC, Dion Y, Rioux S et al. 2005 - Metabolic profiling and factor analysis to discriminate quantitative resistance in wheat cultivars against fusarium head blight. Physiological and Molecular Plant Pathology 66, 119-133.

Hückelhoven R. 2007 - Cell Wall-Associated Mechanisms of Disease Resistance and Susceptibility. Annual Review of Phytopathology 45, 101-127.

Jayalakshmi SK, Mahalinga DM, Gangadhar. 2003 - Source of resistance powdery mildew disease in mung bean, recent development in the diagnosis and management of plant disease. Sarhad Journal of Agriculture 5, 31-32.

Jones OAH, Maguire ML, Griffin JL, Jung YH et al. 2011 - Using metabolic profiling to assess plant-pathogen interactions: An example using rice (Oryza sativa) and the blast pathogen Magnaporthe grisea. European Journal of Plant Pathology 129, 539-554.

Kachroo A, Kachroo P. 2009 - Fatty Acid-Derived Signals in Plant Defense. Annual Review of Phytopathology 47, 153-176.

Kanchiswamy CN, Malnoy M, Maffei ME. 2015 - Chemical diversity of microbial volatiles and their potential for plant growth and productivity. Frontiers in Plant Science 6, 1-23.

Kawasaki T, Koita H, Nakatsubo T, Hasegawa K et al. 2006 - Cinnamoyl-CoA reductase, a key enzyme in lignin biosynthesis, is an effector of small GTPase Rac in defense signaling in rice. Proceedings of the National Academy of Sciences 103, 230-235.

Keurentjes JJB, Fu J, De Vos CHR, Lommen A et al. 2006 - The genetics of plant metabolism. Nature Genetics 38, 842-849.

Kopka J, Schauer N, Krueger S, Birkemeyer C et al. 2005 - The Golm Metabolome Database. Bioinformatics 21, 1635-1638.

Krishnan P, Kruger NJ, Ratcliffe RG. 2005 - Metabolite fingerprinting and profiling in plants using NMR. Journal of Experimental Botany 255-265

Li Y, Song N, Zhao C, Li F et al. 2016 - Application of glycerol for induced powdery mildew resistance in Triticum aestivum L. Frontiers in Physiology 7, 1-13.

Lisec J, Schauer N, Kopka J, Willmitzer L, Fernie AR. 2006 - Gas chromatography mass spectrometry-based metabolite profiling in plants. Nature Protocols 1, 387-396.

Malhotra SK, Singh A. 2000 - Diversity for resistance to powdery mildew in peas. Legume Research 23, 69-70.

Moseman JG. 1966 - Genetics of Powdery Mildews. Annual Review of Phytopathology 4, 269288.

Pande S, Sharma M, Kumari S, Gaur P et al. 2009 - Integrated foliar diseases management of legumes, In Ali M [ed.], Indian Society of Pulses Research and Development, Indian Institute of Pulses Research, Kanpur, India 143-161

Paranidharan V, Abu-Nada Y, Hamzehzarghani H, Kushalappa AC et al. 2008 - Resistance-related metabolites in wheat against Fusarium graminearum and the virulence factor deoxynivalenol (DON). Botany 86, 1168-1179.

Pathak N, Singh M, Mishra M, Singh D et al. 2015 - Field Screening of Mungbean Genotypes and the Role of Total Soluble Sugars and Phenols against Powdery Mildew Resistance. Indian Journal of Plant Genetic Resources 28, 303.

Poehlman JM. 1992 - 30 Choice Reviews Online The mungbean. Oxford and IBH Publication, New Delhi.

Reddy KS, Dhanasekar P, Dhole VJ. 2008 - A review on powdery mildew disease resistance in mungbean. J. Food Legumes 21, 151-155.

Rojas CM, Senthil-Kumar M, Tzin V, Mysore KS. 2014 - Regulation of primary plant metabolism during plant-pathogen interactions and its contribution to plant defense. Frontiers in Plant Science 5, 1-12. 
Sana TR, Fischer S, Wohlgemuth G, Katrekar A et al. 2010 - Metabolomic and transcriptomic analysis of the rice response to the bacterial blight pathogen Xanthomonas oryzae pv. oryzae. Metabolomics 6, 451-465.

Schauer N, Fernie AR. 2006 - Plant metabolomics: towards biological function and mechanism. Trends in Plant Science 11, 508-516.

Schauer N, Semel Y, Roessner U, Gur A et al. 2006 - Comprehensive metabolic profiling and phenotyping of interspecific introgression lines for tomato improvement. Nature Biotechnology 24, 447-454.

Shanmugasundaram S, Kim DH. 1996 - Mungbean. In: P. N. Bahl, and P. M. Salimath (eds), Genetics, Cytogenetic and Breeding of Crop Plant. Science Publishers, Enfield, New Hampshire.

Tarpley L, Duran AL, Kebrom TH, Sumner LW. 2005 - Biomarker metabolites capturing the metabolite variance present in a rice plant developmental period. BMC Plant Biology 5.

Thomas J, Raj Kumar R, Mandal AKA. 2006 - Metabolite profiling and characterization of somaclonal variants in tea (Camellia spp.) for identifying productive and quality accession. Phytochemistry 67, 1136-1142.

Vimala R, Suriachandraselvan M. 2008 - Influence of antagonistic agent, plant products and chemical agents on the powdery mildew disease of bhendi and its production. J. of Biopesticides 1, 130-133.

Walters DR, Mackintosh CA. 1997 - Control of plant disease by perturbation of fungal polyamine metabolism. Physiologia Plantarum 100, 689-695.

Yang W, Miller SA, Scott JW, Jone JB, Ranscis DM. 2005 - Ming tomato genome sequence database for molecular markers: application to bacterial resistance and marker assisted selection. Acta Hort (ISHS) 695, 241-250. 